\title{
60 YEARS OF NEUROENDOCRINOLOGY The posterior pituitary, from Geoffrey Harris to our present understanding
}

\section{Gareth Leng, Rafael Pineda, Nancy Sabatier and Mike Ludwig}

Centre for Integrative Physiology, University of Edinburgh, Hugh Robson Building, George Square, Edinburgh EH9 8XD, UK
Correspondence should be addressed to $G$ Leng

Email

Gareth.Leng@ed.ac.uk

\begin{abstract}
Geoffrey Harris pioneered our understanding of the posterior pituitary, mainly with

experiments that involved the electrical stimulation of the supraoptico-hypophysial tract. In the present essay, we explain how his observations included clues to the pulsatile nature of the oxytocin signal - clues that were followed up by subsequent workers, including his students and their students. These studies ultimately led to our present understanding of the milk-ejection reflex and of the role of oxytocin in parturition. Discoveries of wide significance followed, including: the recognition of the importance of pulsatile hormone secretion; the recognition of the importance of stimulus-secretion coupling mechanisms in interpreting the patterned electrical activity of neurons; the physiological importance of peptide release in the brain; the recognition that peptide release comes substantially from dendrites and can be regulated independently of nerve terminal secretion; and the importance of dynamic morphological changes to neuronal function in the hypothalamus. All of these discoveries followed from the drive to understand the milk-ejection reflex. We also reflect on Harris's observations on vasopressin secretion, on the effects of stress, and on oxytocin secretion during sexual activity.
\end{abstract}

Key Words

\section{Introduction}

The comfortable view of science is that it is a uniquely disinterested activity of gathering objective and unbiased observations which, by the selfless collaboration and co-operation of transnational armies of scientists, lead us ever closer to objective truth. A less comfortable view was expressed by Popper (1959): 'Science does not rest upon solid bedrock. The bold structure of its theories rises, as it were, above a swamp', and in his view, it is the 'bold ideas, unjustified anticipations and speculative thought' of individual scientists that mark the best science and that drive progress. There is certainly a flow in scientific understanding: one observation leads to the next, and each question answered raises another. And that flow is certainly perturbed (if not quite guided) by those whose bold ideas gain currency. In the present essay, we trace the impact of the work of Geoffrey Harris on our understanding of the posterior pituitary gland, although whether our understanding would be different had Harris become an accountant instead of a scientist is something we cannot say: that is one experiment we cannot yet perform.

Published by Bioscientifica Ltd

This paper is part of a thematic review section on 60 years of neuroendocrinology. The Guest Editors for this section.were Ashley Grossman $_{i}$ and Clive Coen. 04/26/2023 12:23:46PM 
Harris won his reputation as the 'father of neuroendocrinology' by conducting incisive experiments which showed that the endocrine cells of the anterior pituitary are regulated by the products of hypothalamic neurons that are secreted into the hypothalamo-pituitary portal circulation (Raisman 1997). If he was bold in this, he was more conservative when it came to the theories of others: in his 1955 monograph, he still inclined to the view that the posterior pituitary contained endocrine cells that were innervated by hypothalamic neurons (Harris 1955). Although he conceded that the neurosecretory origin of the posterior pituitary hormones (Leveque \& Scharrer 1953) was an 'attractive hypothesis', he declared that 'sweeping statements have been made at various times by the protagonists of the neurosecretory hypothesis' and warned that 'such claims as these, which run contrary to a great deal of established data should be taken with reserve' (Harris 1955: 264). In particular, Harris rejected the notion that the Gomorri-stainable material present in the hypothalamo-hypophysial tract was the histological representation of antidiuretic hormone, as had been argued by the Scharrers. He thought that the amount of oxytocic and antidiuretic activity present in the hypothalamus was too low to be consistent with the hypothalamus being the site of production. Finally, he disputed the evidence that neural stalk section could be followed by a partial regeneration of the neural lobe - evidence which suggested that the regeneration of nerve terminals was sufficient to support secretion in the absence of endocrine cells (Harris 1955: 262-265).

Nevertheless, Harris pioneered our understanding of the posterior pituitary, mainly with experiments that involved the electrical stimulation of the supraopticohypophysial tract. At the outset of those experiments, it was known that extracts of the posterior pituitary could stimulate the let-down of milk in lactating animals, and Ely \& Petersen (1941) had shown that the blood of cows which had been milked contained something that could evoke milk let-down in the isolated udder. They proposed that this substance came from the posterior pituitary and was released by suckling, but Selye (1934) had earlier proposed that lactation could be explained by the stimulation of prolactin production from the anterior pituitary, and several reports had appeared that suggested that lactation could proceed normally even after sectioning the neural stalk.

Accordingly, with his student Barry Cross, Harris set out to test these two hypotheses. He had concluded (Harris 1948a) that direct electrical stimulation was ineffective in triggering secretion from the anterior pituitary, but the posterior pituitary was innervated by a nervous tract - the supraoptico-hypophysial tract. Cross \& Harris (1950, 1952) showed that the electrical stimulation of this tract caused an increase in intramammary pressure in lactating rabbits, which suggested that the pituitary contains a releasable factor that can induce milk let-down. Harris et al. (1969) later showed that the mammary response depended strongly on the stimulus frequency - only at frequencies in excess of $40 \mathrm{~Hz}$ was there an appreciable response - a finding that would prove to be prescient (Fig. 1A and B).

In 1966, Yagi et al. showed that electrical stimuli applied to the neural stalk triggered action potentials that were conducted antidromically to the neurosecretory cell bodies, but the utility of this seemed limited, because both the site of stimulation and the site of recording required precise stereotaxic control (Yagi et al. 1966). However, Cross, who was at that point Professor of Anatomy at Bristol, saw that the site of the stimulating electrode could be precisely controlled in lactating rats by ensuring that it was positioned where the stimulation would elicit a rise in intramammary pressure (Sundsten et al. 1970). This opened the way to studying magnocellular neurons in vivo, and Jon Wakerley and Dennis Lincoln, working in Cross's department, used this approach to study how the electrical activity of 'antidromically identified' magnocellular neurons regulate oxytocin and vasopressin secretion.

\section{The milk-ejection reflex}

There was still no real understanding of the milk-ejection reflex and, in particular, no appreciation that the reflex was intermittent. The breakthrough came when Wakerley \& Lincoln (1973) showed that during suckling, some of the antidromically identified cells in the supraoptic and paraventricular nuclei showed brief, synchronised highfrequency discharges (about $1-2 \mathrm{~s}$ at $50 \mathrm{~Hz}$ ) at intervals of about $10 \mathrm{~min}$, each of which was followed about $10 \mathrm{~s}$ later by an abrupt increase in intramammary pressure, which is a marker of milk let-down in the mammary glands (Fig. 1D). It became clear that these bursts, which led to pulses of oxytocin secretion, were approximately synchronised among all of the magnocellular oxytocin cells in the hypothalamus. As a corollary, other magnocellular neurons that were antidromically identified as projecting to the posterior pituitary, but that did not participate in this bursting activity, could be assumed to be vasopressin cells.

Exactly why pulsatile secretion was a critically important phenomenon was not immediately apparent,

Published by Bioscientifica Ltd 
A

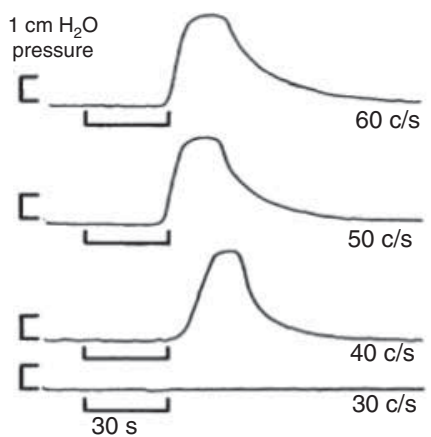

D
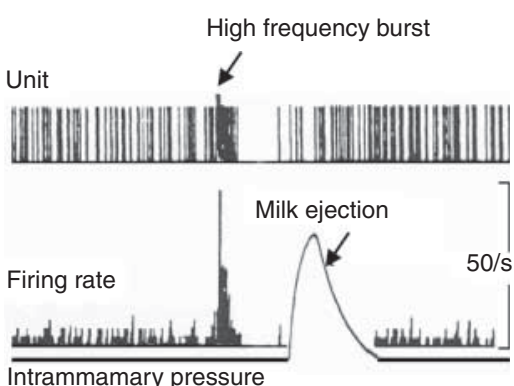

B

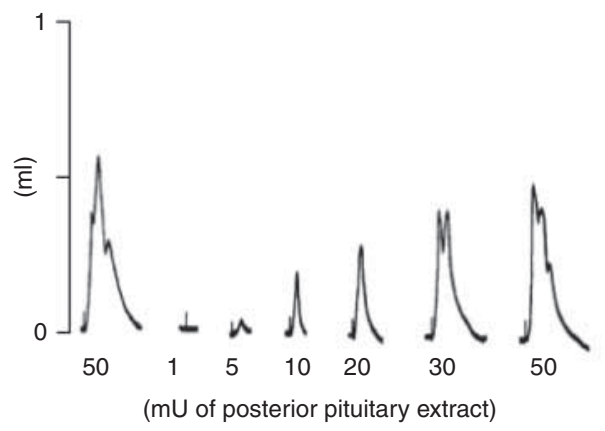

$\mathrm{E}$

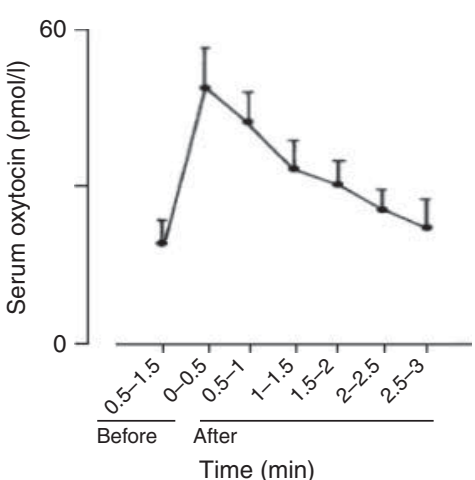

C

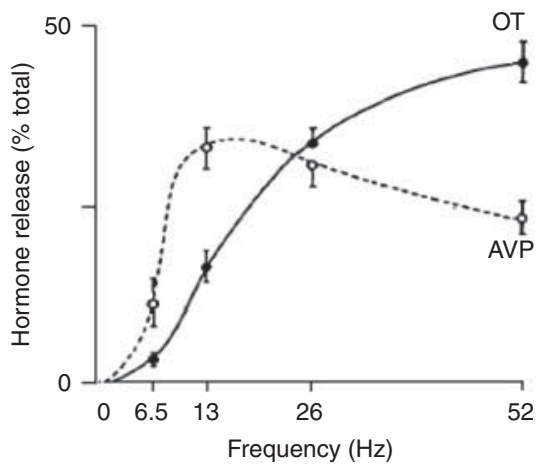

$\mathrm{F}$

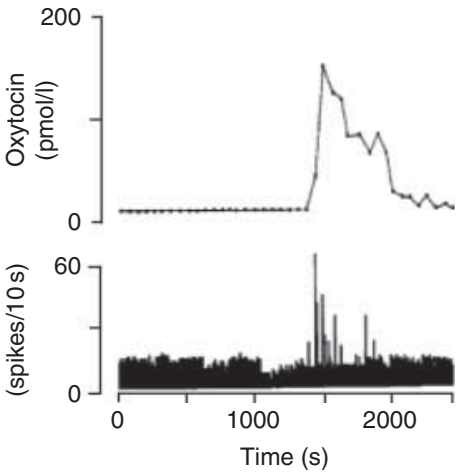

Figure 1

(A) Harris and co-workers showed that electrical stimulation of the neural stalk in lactating rabbits resulted in a sharp rise in intramammary pressure, and they inferred that this was the consequence of oxytocin secreted from the posterior pituitary. They noted that the response to stimulation depended strongly on the frequency of stimulation. The explanation for this has two components. First, the response of the mammary gland to oxytocin is non-linear. Reproduced, with permission from The Physiological Society, from Harris GW, Manabe Y \& Ruf KB (1969) A study of the parameters of electrical stimulation of unmyelinated fibres in the pituitary stalk. Journal of Physiology 203 67-81. Copyright 1969 The Physiological Society. (B) The rabbit mammary gland shows a threshold response to i.v. injection of $10 \mathrm{mU}$ oxytocin and a near-maximal response to a dose of $50 \mathrm{mU}$. Second, the secretion of oxytocin is greatly facilitated by increasing the frequency of stimulation. Reproduced, with permission, from Cross BA \& Harris GW (1952) The role of the neurohypophysis in the milk ejection reflex. Journal of Endocrinology 8 148-161. (C) The amount of oxytocin (and vasopressin) that is released from the rat posterior pituitary gland in vitro in response to a fixed number of electrical stimulus pulses varies markedly with the frequency at which the pulses are applied (the graph plots hormone release in response to 156 pulses at each frequency).

but an important clue lay in Harris's observation, alluded to in the previous section, that the electrical stimulation of the posterior pituitary would only evoke a strong intramammary pressure response if relatively high frequencies of stimulation were used (Harris et al. 1969). The explanation for this has two elements (Fig. 1). First, the response of the mammary gland to a bolus of oxytocin is non-linear and has quite a narrow dynamic range: there
Reproduced, with permission, from Bicknell RJ (1988) Optimizing release from peptide hormone secretory nerve terminals. Journal of Experimental Biology 139 51-65. Copyright 1988 The Company of Biologists Limited. (D) During the milk-ejection reflex (MER), oxytocin neurons discharge short bursts (1-3 s) at a spike frequency that averages $40-50$ spikes/s (i.e. at a frequency that optimises the efficiency of secretion and that evokes a sharp rise in intramammary pressure). Reproduced, with permission from The Physiological Society, from Lincoln DW \& Wakerley JB (1974) Electrophysiological evidence for the activation of supraoptic neurones during the release of oxytocin. Journal of Physiology 242 533-554. Copyright 1974 The Physiological Society. (E) This response is indeed attributable to a pulse of oxytocin, as measured in the blood by RIA. Reproduced, with permission, from Higuchi T, Honda K, Fukuoka T, Negoro H \& Wakabayashi K (1985) Release of oxytocin during suckling and parturition in the rat. Journal of Endocrinology 105 339-346. As shown in $(F)$, similar bursts are observed during parturition. Reproduced, with permission, from Summerlee AJ, Paisley AC, O'Byrne KT, Fairhall KM, Robinson IC \& Fletcher J (1986) Aspects of the neuronal and endocrine components of reflex milk ejection in conscious rabbits. Journal of Endocrinology 108 143-149.

is a threshold dose that must be exceeded before any effect is observed, and above this threshold, the response to higher doses of oxytocin rises swiftly to a maximum. Thus, the mammary gland seems to require pulsatile activation especially because if oxytocin is applied continuously rather than in pulses, then the response of the gland rapidly diminishes. Second, how much oxytocin is secreted in response to electrical stimulation depends

Published by Bioscientifica Ltd 
on the frequency of stimulation - more oxytocin is secreted per stimulus pulse when the stimuli are clustered closely together (Fig. 1C). This frequency facilitation of stimulus-secretion coupling can be attributed to several factors. A solitary spike invading an axon in the pituitary will not invade all of the terminals of that axon, and in those it does invade, it will produce only a brief rise in intracellular calcium - the essential trigger for vesicle exocytosis. However, during a burst of spikes, a progressive increase in extracellular $\left[\mathrm{K}^{+}\right]$depolarises the axons and endings in the neural lobe, which thereby secures a more complete invasion of the terminal arborisation. Moreover, successive spikes in a burst are progressively broadened, which induces a progressively larger calcium entry and gives a potentiated signal for exocytosis. As a result, each spike within a burst releases much more oxytocin than that released by the isolated spikes that occur between bursts (Bourque 1991, Leng \& Brown 1997).

The explosive nature of milk-ejection bursts suggested that some positive feedback was involved, so Moss et al. (1972) set about to try to show that oxytocin released from the posterior pituitary had that positive feedback effect. They recorded from magnocellular neurons in rats and rabbits and studied the effects of oxytocin that was administered intravenously and oxytocin that was administered directly to the neurons by iontophoresis. The results were disconcerting - oxytocin had a dramatic excitatory effect on many magnocellular neurons. This seemed to be a specific effect, because non-neurosecretory cells were unaffected and vasopressin that was applied in the same way had no effect. However, even at large doses, oxytocin had no effect at all when given intravenously.

At that time, there was no evidence that oxytocin was released centrally, and indeed it seemed very unlikely that it would be. There was no strong evidence of axon collaterals, and the evidence tended to suggest that if there were any recurrent collaterals, then their effect was probably inhibitory. Several reports had appeared of 'recurrent inhibition' in the magnocellular system reports that were later shown by Leng \& Dyball (1984) to be based on misinterpreted evidence. Moss et al. (1972) recognised that the ineffectiveness of intravenous oxytocin meant that oxytocin secreted from the pituitary did not find its way back into the brain. Accordingly, they concluded that the excitatory action of oxytocin on oxytocin cells was a pharmacological phenomenon that had no physiological significance.

However, this view was soon to change. Richard et al. (1991) in France showed that oxytocin was released into the hypothalamus during suckling, that small amounts of oxytocin injected into the brain of lactating rats dramatically facilitated the milk-ejection reflex, and that central injections of oxytocin antagonist could block the reflex. Thus, it seemed that oxytocin given centrally was somehow able to 'orchestrate' the intermittent bursting activity of oxytocin cells that had first been seen by Wakerley \& Lincoln (1973). This was the first convincing demonstration of a physiological role for a peptide in the brain, and it led the way to a transformation of our understanding of information processing in the nervous system. We now know that more than one hundred different neuropeptides are expressed in different neuronal populations and that most if not all neurons in the brain release one or more peptide messengers as well as a conventional neurotransmitter. Because peptides have a relatively long half-life and act at receptors with nanomolar affinity, their actions are not confined to targets that are in direct apposition to the site of release. Importantly, peptide signals in the brain often have organisational and activational roles that seem more akin to the roles of hormones in the periphery (Ludwig \& Leng 2006). We now take for granted this understanding that peptides in the brain can have specific functional roles, because of our knowledge of many peptides that evoke coherent behavioural responses when they are injected into the brain.

In Germany, Landgraf et al. (1992) began measuring oxytocin and vasopressin release in the brain using the new technique of microdialysis. They at first assumed that they were measuring the release from nerve terminals in the brain. However, there were accumulating discrepancies between the central release and peripheral release of the peptides, and when Morris \& Pow (1991) showed that oxytocin and vasopressin could be released from all of the compartments of magnocellular neurons, not just the nerve terminals, Landgraf's student Ludwig (1998) realised that measurements of oxytocin and vasopressin in the magnocellular nuclei reflect the release of these neurons from the soma and dendrites, not from nerve terminals (Figs 2 and 3). Furthermore, he recognised that this dendritic release must somehow be regulated independently of terminal release.

This was a breakthrough - but how then was dendritic release regulated? Intriguing data from the laboratories of Theodosis and Hatton had indicated that in lactating animals, there was a morphological reorganisation of the supraoptic nucleus that might facilitate dendro-dendritic interactions: normally, the dendrites are separated from each other by interleaved glial cell processes, but in lactation, these processes are retracted,

Published by Bioscientifica Ltd 

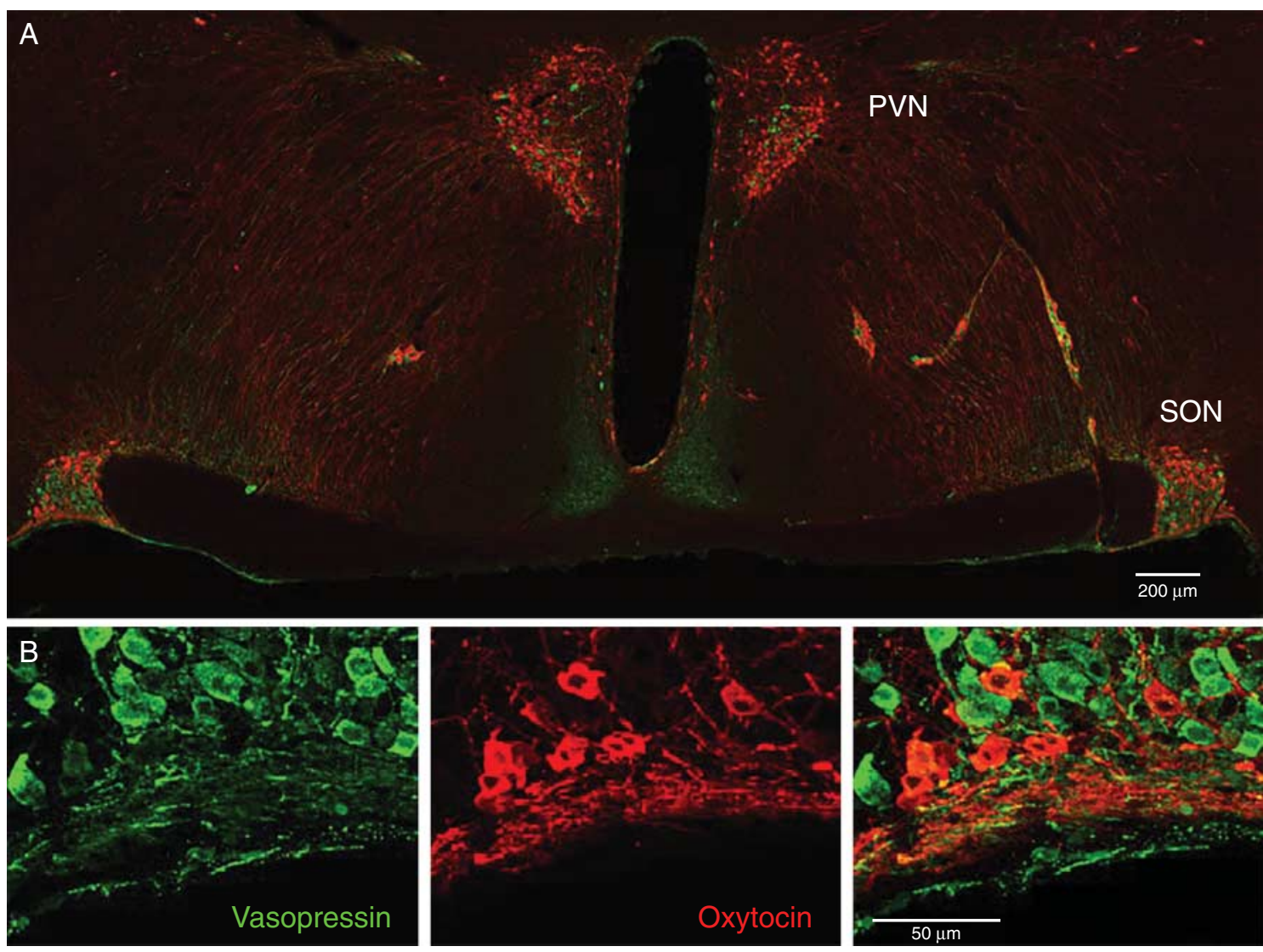

Figure 2

(A) Vasopressin and oxytocin that circulate in the plasma are synthesised by magnocellular neurons whose cell bodies are located mainly in the paraventricular (PVN) and the supraoptic nuclei (SON) of the hypothalamus (vasopressin cells are immunostained with fluorescent green and oxytocin

which puts the dendrites of oxytocin neurons in direct apposition to each other within 'bundles' of dendrites (Hatton 1990, Theodosis \& Poulain 1993). However, there was a stumbling block: oxytocin cells only show synchronous bursting during suckling and parturition - even during lactation, other stimuli increases their activity but never elicited bursts. Dyball \& Leng (1986), working in Cross's group at the Babraham Institute, where Cross had become the director, pursued the idea that some kind of positive feedback was involved. They thought it possible that a recurrent excitatory circuit that involved interneurons was responsible - but although the intense stimulation of the neural stalk massively activated the cells in the supraoptic nucleus, it never triggered recurrent excitation in those cells. The stimulation was not without effect on the milk-ejection reflex, but the effects were quite subtle - there was a facilitation of bursting but only when stimuli were applied quite close to when a burst was expected to happen anyway. cells with fluorescent red). (B) The peptide immunostaining is punctate and represents individual or aggregates of large dense-cored vesicles, and in dendrites, the vesicles are particularly abundant.

Leng and Ludwig began to work together to address a basic question - would the intense electrical stimulation of the neural stalk actually release any vasopressin or oxytocin in the supraoptic nucleus? In experiment after experiment, the answer was frustratingly negative - there was no sign of release measured by microdialysis following electrical activation (Ludwig et al. 2002). Release could be evoked consistently by other kinds of stimulation, but without a link to the electrical activity of the cells, where was the positive feedback effect?

The next breakthrough came again from the Richard's lab, with the demonstration that oxytocin could cause a mobilisation of intracellular calcium stores in oxytocin cells (Lambert et al. 1994). How might that be relevant?

Working on the gonadotroph cells of the anterior pituitary gland, another of Harris's students, George Fink, had shown something remarkable. In oestrogen-primed rats, the secretion of luteinising hormone $(\mathrm{LH})$ in response to gonadotrophin-releasing hormone $(\mathrm{GnRH})$ increases

Published by Bioscientifica Ltd 

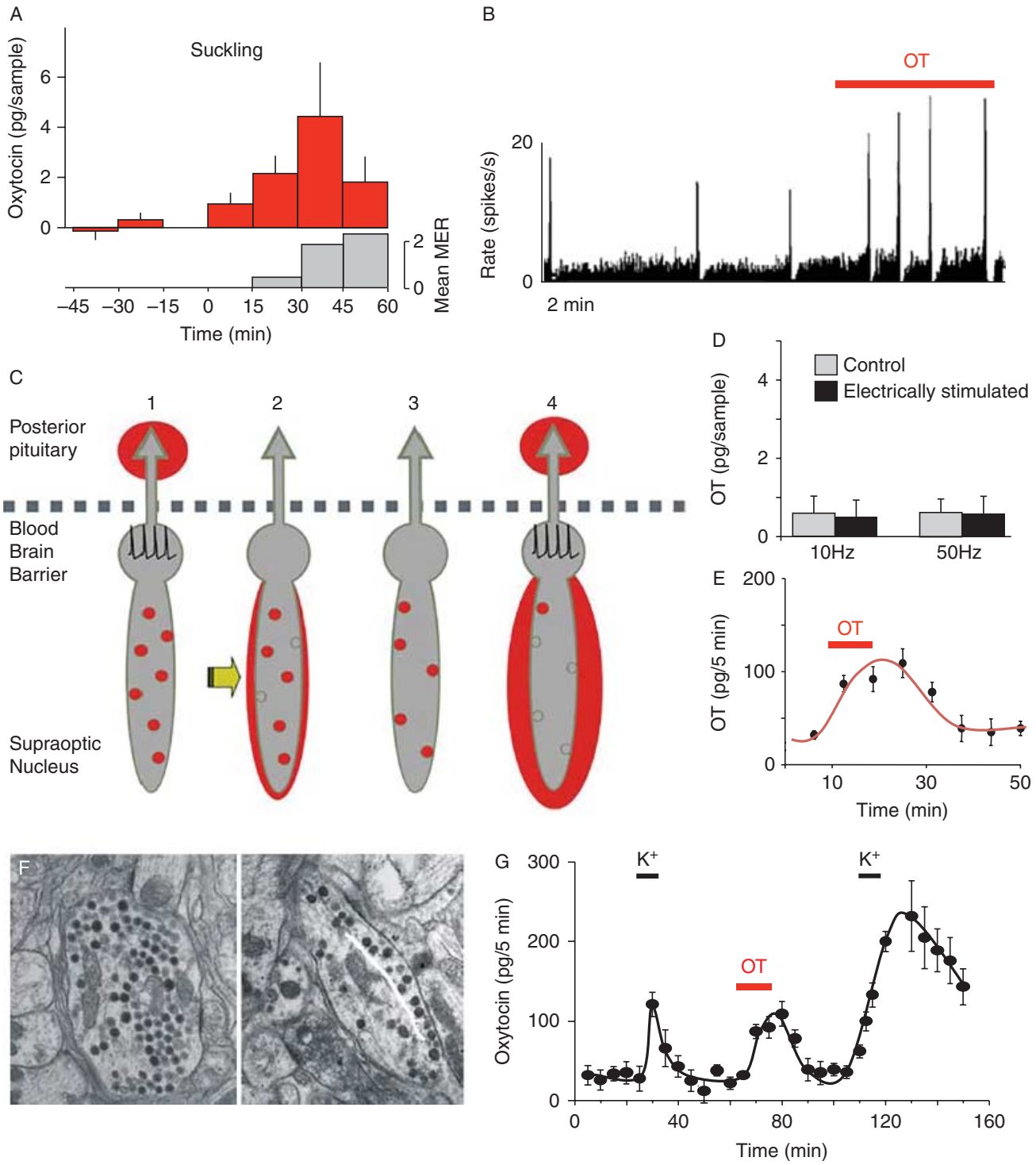

Figure 3

(A) Push-pull perfusion studies have shown that dendritic oxytocin release increases before the high-frequency burst activity of oxytocin neurons which is associated with the milk-ejection reflex. Reproduced, with permission, from Moos F, Poulain DA, Rodriguez F, Guerne $Y$, Vincent JD \& Richard P (1989) Release of oxytocin within the supraoptic nucleus during the milk rejection reflex in rats. Experimental Brain Research 76 593-602. Copyright 1989 Springer-Verlag. (B) The i.c.v. injection of oxytocin increases the burst amplitude and the burst frequency of oxytocin cells, which shows that central release regulates the milk-ejection reflex. Reproduced, with permission, from Brown D, Fontanaud P \& Moos FC (2000) The variability of basal action potential firing is positively correlated with bursting in hypothalamic oxytocin neurones. Journal of Neuroendocrinology $12506-$ 520. Copyright 2000 Blackwell Science Ltd. (C) Dendritic oxytocin release can be conditionally primed. Reproduced, with permission, from Ludwig M \& Leng G (2006) Dendritic peptide release and peptide-dependent behaviours. Nature Reviews Neuroscience 7 126-136. Copyright 2006, Rights Managed by Nature Publishing Group. (D) Under normal conditions, dendritic peptide release is not activated by electrical (spike) activity. This is indicated by the lack of dendritic oxytocin release in response to electrical

stimulation of the neural stalk (light grey columns). (E) A conditional signal (arrow), such as oxytocin itself, triggers release from dendrites independently of the electrical activity. Reproduced, with permission, from Ludwig M, Sabatier N, Bull PM, Landgraf R, Dayanithi G \& Leng G (2002) Intracellular calcium stores regulate activity-dependent neuropeptide release from dendrites. Nature 418 85-89. Copyright 2002, Rights Managed by Nature Publishing Group. (F) The conditional signal also primes dendritic stores. Priming occurs partially by the relocation of dendritic large densecore vesicles closer to the dendritic plasma membrane. Reproduced, with permission, from Tobin VA, Hurst G, Norrie L, Dal Rio FP, Bull PM \& Ludwig $M$ (2004) Thapsigargin-induced mobilization of dendritic densecored vesicles in rat supraoptic neurons. European Journal of Neuroscience 19 2909-2912. Copyright 2004 Federation of European Neuroscience Societies. (G) After oxytocin-induced priming, the vesicles are available for activitydependent release for a prolonged period. Reproduced, with permission, from Ludwig M, Sabatier N, Bull PM, Landgraf R, Dayanithi G \& Leng G (2002) Intracellular calcium stores regulate activity-dependent neuropeptide release from dendrites. Nature 418 85-89. Copyright 2002, Rights Managed by Nature Publishing Group.

Published by Bioscientifica Ltd 
with successive exposures to GnRH, a phenomenon that Fink (1995) called 'self-priming'. With Morris and others, Fink showed that between exposures to GnRH, there is a 'margination' of secretory granules in gonadotrophs: how much LH is secreted in response to GnRH depends on how many granules lie close to the plasma membrane and GnRH could trigger the relocation of granules to these sites (Lewis et al. 1986). This depends on the mobilisation by GnRH of intracellular calcium stores, so Leng and Ludwig, knowing that the release of neurosecretory granules in response to electrical activity was likely to depend on those granules being close to the site of depolarisation-induced calcium entry, wondered if something similar was happening in the dendrites of magnocellular neurons. By 'retrodialysis' - using microdialysis probes to deliver a substance rather than to collect one - they applied thapsigargin directly to the supraoptic nucleus to evoke a large increase in intracellular calcium in the magnocellular cells; then, long after the direct effects of the thapsigargin had worn off, they applied electrical stimulation to the neural stalk. Now, finally, they could see a dramatic electrically-evoked release of both oxytocin and vasopressin in the supraoptic nucleus as well as from the pituitary. They went on to show that the same 'priming' could be seen in response to peptides that evoked intracellular calcium mobilisation - including (for oxytocin release) oxytocin itself (Ludwig et al. 2002).

Rossoni et al. (2008) were then able to build a computational model of the oxytocin system that incorporated these phenomena and that reproduced the bursting behaviour of oxytocin neurons observed during the milk-ejection reflex. That model explained how bursts could be generated by dendro-dendritic intercommunication and could be rapidly propagated through the oxytocin cells in a hypothalamic nucleus, but it left unexplained how oxytocin cells in the two supraoptic and two paraventricular nuclei come to be activated simultaneously. One possibility lies in recognising that the appearance of the separation of the four nuclei is misleading - many magnocellular neurons are located between the main nuclear aggregations, some as small, 'accessory' nuclei and some as scattered neurons. Thus, if these neurons share dendro-dendritic contacts with the major aggregations, they might complete a network that links all of the nuclei. A second possibility arises from the work of Knobloch et al. (2012), who found that the paraventricular nucleus contains some nonneuroendocrine oxytocin neurons that innervate oxytocin cells in the supraoptic nucleus.

\section{Parturition}

Oxytocin's role in milk ejection is indispensable: animals that lack oxytocin are unable to feed their offspring (Nishimori et al. 1996, Young et al. 1996). By contrast, although oxytocin is named after its effects on uterine contractility, mice that lack oxytocin are still able to deliver young relatively normally, but whether this is generally the case in all mammals still remains unclear. In 1941, Ferguson reported that in the pregnant rabbit, distension of the uterus and cervix could induce the secretion of oxytocin, but in that same year, Dey et al. reported on the effects of lesions to the supraopticohypophysial tract in pregnant guinea pigs: of the 16 labours studied, ten were prolonged and difficult and ended in the death of the mother or the delivery of dead foetuses, but six were apparently normal (Dey et al. 1941, Ferguson 1941). Harris had shown that the electrical stimulation of the neural stalk could evoke strong uterine contractions, but it remained unclear whether the effects of oxytocin on the uterus reflected an active role of oxytocin in parturition or a pharmacological effect without real physiological significance (Harris 1948b). However, Harris's papers prompted Gunther (1948) to write a letter to the BMJ: she had observed labour in a woman who was still lactating after the birth of a previous child and noticed that beads of milk appeared at the nipples during each uterine contraction. Many factors were known to be capable of eliciting uterine contractions, but only oxytocin was known to induce milk let-down, so Gunther speculated that the uterine contractions provoked the release of oxytocin, which acted in a positivefeedback manner to support parturition.

However, by the end of the 1950s and the beginning of the 1960s, it was recognised that the plasma of pregnant women contained an enzyme - oxytocinase - that could potently degrade oxytocin and that the levels of oxytocinase increased markedly towards term (Melander 1961). This greatly complicated measuring oxytocin in pregnancy and also raised fresh doubt about the physiological role of oxytocin: if oxytocin was important for parturition, it seemed to make no sense that the placenta should produce large amounts of an enzyme that destroyed it.

Then, in the 1980s, Summerlee and colleagues, working in Cross's former department at Bristol, published a series of papers that reported the activity of oxytocin neurons recorded over prolonged periods in conscious rats and rabbits through parturition and lactation (Summerlee 1981, Summerlee \& Lincoln 1981, Paisley \& Summerlee 1984, O'Byrne et al. 1986). These studies

Published by Bioscientifica Ltd 
achieved two things of particular importance: first, the milk-ejection reflex as described in anesthetised rats was essentially identical to the reflex in conscious rats; and second, similar bursting activity was generated during parturition, linked to the delivery of young. The insight that oxytocin secretion is pulsatile during parturition cast a new light on the high levels of oxytocinase in the plasma of pregnant women, because although these high levels of oxytocinase diminish basal levels of oxytocin, they would also be expected to 'sharpen' the pulses of oxytocin by shortening their half-life. By frequent blood sampling combined with rigorous methods to inactivate oxytocinase in those samples, Fuchs et al. (1991) confirmed that spontaneous delivery in women is indeed associated with frequent short pulses of oxytocin secretion.

But are pulses necessary for parturition in the way that they are for milk ejection? This is less clear, because the uterus will continue to contract in the continued presence of oxytocin. Nevertheless, it seems that pulses are indeed a more effective way for oxytocin to drive parturition. At Babraham, Luckman et al. (1993) tested this in the rat by first interrupting parturition with morphine - a potent inhibitor of oxytocin neurons in the rat - and then attempting to re-establish parturition by giving oxytocin either as pulses or as a continuous infusion. Normal parturition could be reinstated by giving pulses of oxytocin at 10 min intervals, whereas much higher doses were needed to achieve a similar outcome by the continuous infusion of oxytocin.

It is now generally accepted that in all mammalian species, oxytocin secreted from the posterior pituitary plays a role in the expulsive phase of labour. Apart from its direct effects on the uterine myometrium, oxytocin also stimulates prostaglandin release by its actions on the decidua/uterine epithelium. Oxytocin is not strictly essential, seeing as other mechanisms can generally compensate for its absence, but it is secreted in very large amounts during labour; it also acts on the uterus, which expresses greatly increased levels of oxytocin receptor at term, by either acutely blocking oxytocin release or slowing parturition (Blanks \& Thornton 2003, Russell et al. 2003). The trigger for initiating parturition varies between species, but it seems that oxytocin is commonly a driver for uterine contractions once parturition has begun (Russell et al. 2003, Arrowsmith \& Wray 2014). Oxytocin may also play some part in the initiation of labour, but in women, other paracrine mechanisms are more important for this (Kamel 2010). However, oxytocin antagonists are used to avert threatened preterm labour (Usta et al. 2011).

\section{Sexual activity}

Harris (1947) showed that the stimulation of the posterior pituitary evoked robust uterine contractions in the oestrous or oestrogenised rabbit and that these effects could be mimicked by injections of pituitary extract. He knew that this did not demonstrate a physiological role for oxytocin in labour and that Ferguson's (1941) findings were more pertinent to that issue. However, he was intrigued that oxytocin caused uterine contractions in the empty, non-pregnant uterus, and he speculated that coitus might trigger the secretion of oxytocin to facilitate the transport of seminal fluid up the female reproductive tract. He went on to find a novel way of testing whether coitus triggered oxytocin secretion in women.

As described in the previous section, Gunther (1948) had reported the appearance of beads of milk in a lactating woman during labour, and this had impressed Harris as good evidence of the active secretion of oxytocin. In 1953, his colleague Pickles (1953) made a similar observation, this time of a lactating woman who had experienced milk let-down immediately after achieving orgasm. Together, Harris \& Pickles (1953) set about to see if this was a common occurrence. Their approach was wonderfully direct - they asked the wives of their colleagues. Six had noticed milk let-down during some stage of coitus (not necessarily at orgasm), and two others reported the 'tingling experience' in their breasts that they recognised as being the same as the one they experienced during suckling. Because milk let-down is a reflex for which oxytocin is essential, this 'bioassay' was powerful evidence that oxytocin is indeed released during coitus in women, a conclusion that was later confirmed by RIA: there appears to be enhanced secretion in the arousal phase before orgasm (Carmichael et al. 1987), whereas the rises at orgasm itself are generally very small (Blaicher et al. 1999).

Whether the secretion of oxytocin into blood during sexual activity has any physiological role in women is still unclear: Levin (2011) has argued that it plays little if any role in sperm transport. Oxytocin is also secreted into the blood during coitus in female goats (McNeilly \& Ducker 1972), but there is an inconsistent increase in rabbits (Todd \& Lightman 1986), and although oxytocin secretion in ewes increases in the presence of a ram, there is no further rise in secretion during mating itself (Gilbert et al. 1991). Large doses of oxytocin given systemically facilitate lordosis in ovariectomised, oestrogen-primed rats. Because central injections of much smaller amounts of oxytocin have a similar effect, it has been assumed that this effect is mainly a reflection of

Published by Bioscientifica Ltd 
actions within the brain. But because the effects of systemically administered oxytocin appear to depend on the presence of an intact uterus and cervix, peripheral actions may also contribute (Moody \& Adler 1995).

In men, in response to masturbation, Murphy et al. (1987) found an increase in vasopressin secretion but not oxytocin secretion during sexual arousal and a large and robust increase in oxytocin secretion but not vasopressin secretion at ejaculation. Oxytocin and its receptors are expressed in the prostate, penis, epididymis, and testis, and there is good evidence that the peripheral actions of oxytocin support penile erection and ejaculation, and facilitate sperm transport (Corona et al. 2012).

\section{Vasopressin secretion}

Although Harris (1948c) showed that the electrical stimulation of the posterior pituitary in rabbits resulted in the appearance of a substance in the urine that had antidiuretic effects, this was not any great surprise. It was already clear that posterior pituitary extracts had marked antidiuretic effects, that the hormone content of the posterior pituitary was markedly depleted by dehydration, and that the urine of dehydrated animals contained a substance with apparently similar antidiuretic properties to those of posterior pituitary extracts. Verney (1947) had established that intracarotid infusions of hypertonic solutions elicited antidiuresis in dogs, and, through experiments that involved ligations of the internal carotid artery and various nerve sections, he had shown that this antidiuretic response required an intact posterior pituitary and that the osmoreceptors apparently lay in a region of the prosencephalon that is supplied by the internal carotid. The supraoptic nucleus itself was suggested to be a prime candidate for the location of these osmoreceptors, particularly because it was known to be exceptionally densely vascularised. Indeed, this speculation was correct - the magnocellular neurons of the supraoptic and paraventricular nuclei express stretch-sensitive membrane channels, which makes them exquisitely sensitive to volume change; with raised external osmolality, the cells shrink, and this shrinkage results in the activation of a depolarising current (Bourque 2008).

But this mechanism does not work in isolation. The direct depolarisation that results from volume changes is small and not enough in itself to increase the spiking activity of the magnocellular neurons. However, if those neurons are also receiving extensive afferent input, then even a small tonic depolarisation becomes effective, because it increases the probability that depolarisations that arise from afferent input will exceed spike threshold. Thus, although the magnocellular neurons are osmoreceptors, when they are deafferented, they cannot increase their firing rates in response to osmotic stimulation - this response requires at least a tonic afferent input (Leng et al. 1982). They get such a tonic input from a set of anterior brain structures that includes two circumventricular organs - the subfornical organ and the organum vasculosum of the laminae terminalis - that are also osmoreceptive in the same way that magnocellular neurons are (Bourque 2008). They project to the magnocellular nuclei but also to the nucleus medianus, a midline structure adjacent to the anterior wall of the third ventricle which also projects densely to the magnocellular nuclei. Collectively, these anterior regions have become known as the 'AV3V region'. This region controls not only antidiuresis but also thirst and natriuresis, and it mediates the effects of angiotensin produced by the kidney and those of other circulating hormones of cardiovascular origin (Johnson 1985).

\section{Stress}

Harris's monograph focuses on another aspect of the regulation of vasopressin secretion that is more controversial - the effect of emotional stress. He noted that there was considerable evidence in humans that emotional stress was accompanied by antidiuresis, that Verney had shown this to also be the case in dogs, and that this seemed likely to be the result of vasopressin released from the posterior pituitary. In rats, many behavioural stressors have no clear effect on vasopressin secretion, although they generally do stimulate oxytocin secretion (Gibbs 1986), whereas conditioned fear stimulates oxytocin secretion but inhibits vasopressin secretion (Onaka et al. 1988), and novelty stress inhibits vasopressin secretion but has no effect on oxytocin secretion (Onaka et al. 2003). By contrast, in humans, vasopressin secretion appears to be stimulated by psychological stressors, such as social stress (Siegenthaler et al. 2014) and exam stress (Urwyler et al. 2015).

The physiological significance of this observation is very uncertain. Vasopressin plays an important role in regulating adrenocorticotrophic hormone (ACTH) secretion from the anterior pituitary; it is released into the hypothalamo-hypophysial portal circulation from the terminals of parvocellular and magnocellular neurons of the paraventricular nucleus and acts in concert with corticotrophin releasing factor (CRF) (Antoni et al. 1983). Circulating levels of vasopressin, which are secreted from

Published by Bioscientifica Ltd 
the posterior pituitary, are generally thought to be too low to be effective. However, vasopressin and CRF interact synergistically in stimulating ACTH secretion, so it is possible that in the presence of elevated CRF secretion, vasopressin secretion from the pituitary might become effective. To date, this possibility has not been extensively tested - and Ehrenreich et al. (1996) found no association in human subjects between increases in vasopressin secretion in response to novelty stress and ACTH secretion. Even if vasopressin from the magnocellular system does influence ACTH secretion under some circumstances, it is unclear what adaptive significance there might be. Similarly, the increased secretion of oxytocin in response to many stressors is without both clear physiological effect and adaptive significance. Oxytocin alone is an even weaker ACTH secretagogue than vasopressin is.

\section{The present day}

We now know that oxytocin and vasopressin have numerous peripheral targets that were largely or completely unknown to Harris. There is evidence that, in some species at least, oxytocin is involved in the regulation of natriuresis (Antunes-Rodrigues et al. 1997), osteoblast activity (Di Benedetto et al. 2014), and gastric motility (Qin et al. 2009).

However, the more radical change in our worldview has probably come from the recognition that oxytocin and vasopressin are not only secreted from the posterior pituitary but are also released in the brain, where they have very diverse behavioural effects. Both oxytocin and vasopressin are modulators of social behaviour (Caldwell et al. 2008, Lee et al. 2009, Neumann \& Landgraf 2012). Parvocellular oxytocin and vasopressin neurons in the paraventricular nucleus project to many sites in the CNS and the spinal cord, and vasopressin is also expressed at several other sites in the brain (see de Vries 2008), including in the olfactory bulb, where it has been implicated in social recognition (Tobin et al. 2010). In addition, oxytocin is an important regulator of appetite (Leng et al. 2008) and sexual behaviour (Baskerville \& Douglas 2008). Centrally projecting parvocellular oxytocin and vasopressin neurons play important roles in these behaviours, but the magnocellular neuroendocrine system has also been implicated through dendritic release mechanisms. It now seems clear that many neuroactive substances released in the brain, including oxytocin and vasopressin, can act at a distance from their sites of release (Leng \& Ludwig 2008). Oxytocin and vasopressin have profound effects on behaviours that are exerted at sites that, in some cases, richly express peptide receptors but are innervated by few peptide-containing projections. The release of these peptides is not specifically targeted at synapses, and the long half-life of peptides in the CNS and their abundance in the extracellular fluid mean that after release they can reach their sites of action by what Fuxe has called 'volume transmission' (Fuxe et al. 2012). At their targets, the process of priming allows peptides to functionally reorganise neuronal networks, which provides a substrate for prolonged behavioural effects (Ludwig \& Leng 2006).

Our mechanistic understanding of the magnocellular neurons has undoubtedly achieved great sophistication (Brown et al. 2013), substantially through a concerted drive by many scientists over many years to meet the challenges laid down by Harris and his contemporaries to understand the milk-ejection reflex, the role of oxytocin in parturition, and the nature of the osmoregulatory response of vasopressin cells. Discoveries of wide significance followed this drive, including: the recognition of the importance of pulsatile hormone secretion; the recognition of the importance of stimulus-secretion coupling mechanisms in interpreting the patterned electrical activity of neurons; the physiological importance of peptide release in the brain; the recognition that peptide release comes substantially from dendrites and can be regulated independently of nerve terminal secretion; and the importance of dynamic morphological changes to neuronal function in the hypothalamus. All of these discoveries followed directly from the drive to understand the milk-ejection reflex.

Yet despite the intensity with which magnocellular neurons have been interrogated, these neurons still have the capacity to surprise us. For example, it has only recently become clear that magnocellular vasopressin neurons are exquisitely thermosensitive (Sudbury et al. 2010) and are regulated by circadian inputs (Trudel \& Bourque 2012).

In the present essay (we do not pretend it to be a comprehensive review), we seek to follow the impact of Harris's work. Any such venture risks reinterpreting history to suit a narrative. Yet science is an inescapably social activity, and to neglect this fact would be a mistake. For good and bad, there are 'bandwagons' in our field, some of which crash in blind alleys, as we suspect will be the case for the current bandwagon of paying attention to the effects of the intranasal application of oxytocin and vasopressin, the behavioural consequences of which are generally ascribed, on little evidence, to central actions but which in our view are more likely to be incidental

Published by Bioscientifica Ltd 
consequences of peripheral actions. The bandwagons that Harris set rolling have, however, rolled and rolled, and they have led us inexorably to our present sophisticated and nuanced understanding of the magnocellular neurons.

\section{Declaration of interest}

The authors declare that there is no conflict of interest that could be perceived as prejudicing the impartiality of this review.

\section{Funding}

This work was supported by a grant from the BBSRC (grant number $\mathrm{BB} / \mathrm{J} 004723$ to $\mathrm{M} \mathrm{L}$ and $\mathrm{G} \mathrm{L}$ ) and a Newton International Postdoctoral Fellowship from the Royal Society (to R P).

\section{References}

Antoni FA, Holmes MC \& Jones MT 1983 Oxytocin as well as vasopressin potentiate ovine CRF in vitro. Peptides 4 411-415. (doi:10.1016/01969781(83)90041-4)

Antunes-Rodrigues J, Favaretto AL, Gutkowska J \& McCann SM 1997 The neuroendocrine control of atrial natriuretic peptide release. Molecular Psychiatry 2 359-367. (doi:10.1038/sj.mp.4000308)

Arrowsmith S \& Wray S 2014 Oxytocin: its mechanism of action and receptor signalling in the myometrium. Journal of Neuroendocrinology $\mathbf{2 6}$ 356-369. (doi:10.1111/jne.12154)

Baskerville TA \& Douglas AJ 2008 Interactions between dopamine and oxytocin in the control of sexual behaviour. Progress in Brain Research $170277-290$.

Bicknell RJ 1988 Optimizing release from peptide hormone secretory nerve terminals. Journal of Experimental Biology 139 51-65.

Blaicher W, Gruber D, Bieglmayer C, Blaicher AM, Knogler W \& Huber JC 1999 The role of oxytocin in relation to female sexual arousal. Gynecologic and Obstetric Investigation 47 125-126. (doi:10.1159/ 000010075)

Blanks AM \& Thornton S 2003 The role of oxytocin in parturition. BJOG 110(Suppl 20) 46-51. (doi:10.1046/j.1471-0528.2003.00024.x)

Bourque CW 1991 Activity-dependent modulation of nerve terminal excitation in a mammalian peptidergic system. Trends in Neurosciences 14 28-30. (doi:10.1016/0166-2236(91)90180-3)

Bourque CW 2008 Central mechanisms of osmosensation and systemic osmoregulation. Nature Reviews. Neuroscience 9 519-531. (doi:10.1038/ nrn2400)

Brown D, Fontanaud P \& Moos FC 2000 The variability of basal action potential firing is positively correlated with bursting in hypothalamic oxytocin neurones. Journal of Neuroendocrinology 12 506-520. (doi:10.1046/j.1365-2826.2000.00478.x)

Brown CH, Bains JS, Ludwig M \& Stern JE 2013 Physiological regulation of magnocellular neurosecretory cell activity: integration of intrinsic, local and afferent mechanisms. Journal of Neuroendocrinology $\mathbf{2 5}$ 678-710. (doi:10.1111/jne.12051)

Caldwell HK, Lee HJ, Macbeth AH \& Young WS III 2008 Vasopressin: behavioral roles of an "original" neuropeptide. Progress in Neurobiology 84 1-24. (doi:10.1016/j.pneurobio.2007.10.007)

Carmichael MS, Humbert R, Dixen J, Palmisano G, Greenleaf W \& Davidson JM 1987 Plasma oxytocin increases in the human sexual response. Journal of Clinical Endocrinology and Metabolism 64 27-31. (doi:10.1210/jcem-64-1-27)
Corona G, Jannini EA, Vignozzi L, Rastrelli G \& Maggi M 2012 The hormonal control of ejaculation. Nature Reviews. Urology 9 508-519. (doi:10.1038/nrurol.2012.147)

Cross BA \& Harris GW 1950 Milk ejection following electrical stimulation of the pituitary stalk in rabbits. Nature 166 994-995. (doi:10.1038/ 166994b0)

Cross BA \& Harris GW 1952 The role of the neurohypophysis in the milkejection reflex. Journal of Endocrinology 8 148-161. (doi:10.1677/joe.0. 0080148)

Dey FL, Fisher C \& Ransom SW 1941 Disturbance in pregnancy and labor in guinea-pigs with hypothalamic lesions. American Journal of Obstetrics and Gynecology 42 459-466.

Di Benedetto A, Sun L, Zambonin CG, Tamma R, Nico B, Calvano CD, Colaianni G, Ji Y, Mori G, Grano M et al. 2014 Osteoblast regulation via ligand-activated nuclear trafficking of the oxytocin receptor. PNAS $\mathbf{1 1 1}$ 16502-16507. (doi:10.1073/pnas.1419349111)

Dyball RE \& Leng G 1986 Regulation of the milk ejection reflex in the rat Journal of Physiology 380 239-256. (doi:10.1113/jphysiol.1986. sp016283)

Ehrenreich H, Stender N, Gefeller O, tom Dieck K, Schilling L \& Kaw S 1996 A novelty-related sustained elevation of vasopressin plasma levels in young men is not associated with an enhanced response of adrenocorticotropic hormone (ACTH) to human corticotropin releasing factor (hCRF). Research in Experimental Medicine 196 291-299. (doi:10.1007/ BF02576853)

Ely F \& Petersen WE 1941 Factors involved in the ejection of milk. Journal of Dairy Science 24 211-223. (doi:10.3168/jds.S0022-0302(41)95406-1)

Ferguson JKW 1941 A study of the motility of the intact uterus at term. Surgery, Gynecology \& Obstetrics 73 359-366.

Fink G 1995 The self-priming effect of LHRH: a unique servomechanism and possible cellular model for memory. Frontiers in Neuroendocrinology 16 183-190. (doi:10.1006/frne.1995.1006)

Fuchs AR, Romero R, Keefe D, Parra M, Oyarzun E \& Behnke E 1991 Oxytocin secretion and human parturition: pulse frequency and duration increase during spontaneous labor in women. American Journal of Obstetrics and Gynecology 165 1515-1523. (doi:10.1016/ S0002-9378(12)90793-0)

Fuxe K, Borroto-Escuela DO, Romero-Fernandez W, Ciruela F, Manger P, Leo G, Díaz-Cabiale Z \& Agnati LF 2012 On the role of volume transmission and receptor-receptor interactions in social behaviour: focus on central catecholamine and oxytocin neurons. Brain Research 1476 119-131. (doi:10.1016/j.brainres.2012.01.062)

Gibbs DM 1986 Vasopressin and oxytocin: hypothalamic modulators of the stress response: a review. Psychoneuroendocrinology 11 131-139. (doi:10.1016/0306-4530(86)90048-X)

Gilbert CL, Jenkins K \& Wathes DC 1991 Pulsatile release of oxytocin into the circulation of the ewe during oestrus, mating and the early luteal phase. Journal of Reproduction and Fertility 91 337-346. (doi:10.1530/jrf. 0.0910337)

Gunther M 1948 The posterior pituitary and labour. BMJ 1567. (doi:10.1136/bmj.1.4550.567-b)

Harris GW 1947 The innervation and actions of the neuro-hypophysis; an investigation using the method of remote-control stimulation. Philosophical Transactions of the Royal Society of London. Series B, Biological sciences 232 385-441. (doi:10.1098/rstb.1947.0002)

Harris GW 1948a Electrical stimulation of the hypothalamus and the mechanism of neural control of the adenohypophysis. Journal of Physiology 107 418-429. (doi:10.1113/jphysiol.1948.sp004286)

Harris GW $1948 b$ Hypothalamus and pituitary gland with special reference to the posterior pituitary and labour. BMJ 1 339-342. (doi:10.1136/bmj. 1.4546.339)

Harris GW 1948c The hypothalamus and water metabolism. Proceedings of the Royal Society of Medicine 41 661-666.

Harris GW 1955 Neural control of the pituitary gland. In Monographs of the Physiological Society. London, UK: Edward Arnold. 
Harris GW \& Pickles VR 1953 Reflex stimulation of the neurohypophysis (posterior pituitary gland) and the nature of posterior pituitary hormone(s). Nature 172 1049. (doi:10.1038/1721049a0)

Harris GW, Manabe Y \& Ruf KB 1969 A study of the parameters of electrical stimulation of unmyelinated fibres in the pituitary stalk. Journal of Physiology 203 67-81. (doi:10.1113/jphysiol.1969.sp008850)

Hatton GI 1990 Emerging concepts of structure-function dynamics in adult brain: the hypothalamo-neurohypophysial system. Progress in Neurobiology 34 437-504. (doi:10.1016/0301-0082(90)90017-B)

Higuchi T, Honda K, Fukuoka T, Negoro H \& Wakabayashi K 1985 Release of oxytocin during suckling and parturition in the rat. Journal of Endocrinology 105 339-346. (doi:10.1677/joe.0.1050339)

Johnson AK 1985 The periventricular anteroventral third ventricle (AV3V): its relationship with the subfornical organ and neural systems involved in maintaining body fluid homeostasis. Brain Research Bulletin 15 595-601. (doi:10.1016/0361-9230(85)90209-6)

Kamel RM 2010 The onset of human parturition. Archives of Gynecology and Obstetrics 281 975-982. (doi:10.1007/s00404-010-1365-9)

Knobloch HS, Charlet A, Hoffmann LC, Eliava M, Khrulev S, Cetin AH Osten P, Schwarz MK, Seeburg PH, Stoop R et al. 2012 Evoked axonal oxytocin release in the central amygdala attenuates fear response. Neuron 73 553-566. (doi:10.1016/j.neuron.2011.11.030)

Lambert RC, Dayanithi G, Moos FC \& Richard P 1994 A rise in the intracellular $\mathrm{Ca}^{2+}$ concentration of isolated rat supraoptic cells in response to oxytocin. Journal of Physiology 478 275-287. (doi:10.1113/ jphysiol.1994.sp020249)

Landgraf R, Neumann I, Russell JA \& Pittman QJ 1992 Push-pull perfusion and microdialysis studies of central oxytocin and vasopressin release in freely moving rats during pregnancy, parturition, and lactation. Annals of the New York Academy of Sciences 652 326-339. (doi:10.1111/j.17496632.1992.tb34364.x)

Lee HJ, Macbeth AH, Pagani JH \& Young WS III 2009 Oxytocin: the great facilitator of life. Progress in Neurobiology 88 127-151.

Leng G \& Brown D 1997 The origins and significance of pulsatility in hormone secretion from the pituitary. Journal of Neuroendocrinology 9 493-513.

Leng G \& Dyball RE 1984 Recurrent inhibition: a recurring misinterpretation. Quarterly Journal of Experimental Physiology 69 393-395. (doi:10.1113/expphysiol.1984.sp002814)

Leng G \& Ludwig M 2008 Neurotransmitters and peptides: whispered secrets and public announcements. Journal of Physiology 586 5625-5632. (doi:10.1113/jphysiol.2008.159103)

Leng G, Mason WT \& Dyer RG 1982 The supraoptic nucleus as an osmoreceptor. Neuroendocrinology 34 75-82. (doi:10.1159/000123280)

Leng G, Onaka T, Caquineau C, Sabatier N, Tobin VA \& Takayanagi Y 2008 Oxytocin and appetite. Progress in Brain Research 170 137-151.

Leveque TF \& Scharrer E 1953 Pituicytes and the origin of the antidiuretic hormone. Endocrinology 52 436-447. (doi:10.1210/endo-52-4-436)

Levin RJ 2011 Can the controversy about the putative role of the human female orgasm in sperm transport be settled with our current physiological knowledge of coitus? Journal of Sexual Medicine $\mathbf{8}$ 1566-1578. (doi:10.1111/j.1743-6109.2010.02162.x)

Lewis CE, Morris JF, Fink G \& Johnson M 1986 Changes in the granule population of gonadotrophs of hypogonadal (hpg) and normal female mice associated with the priming effect of LH-releasing hormone in vitro. Journal of Endocrinology 109 35-44. (doi:10.1677/joe. $0.1090035)$

Lincoln DW \& Wakerley JB 1974 Electrophysiological evidence for the activation of supraoptic neurones during the release of oxytocin. Journal of Physiology 242 533-554. (doi:10.1113/jphysiol.1974. sp010722)

Luckman SM, Antonijevic I, Leng G, Dye S, Douglas AJ, Russell JA \& Bicknell RJ 1993 The maintenance of normal parturition in the rat requires neurohypophysial oxytocin. Journal of Neuroendocrinology $\mathbf{5}$ 7-12. (doi:10.1111/j.1365-2826.1993.tb00358.x)
Ludwig M 1998 Dendritic release of vasopressin and oxytocin. Journal of Neuroendocrinology 10 881-895. (doi:10.1046/j.1365-2826. 1998.00279.x)

Ludwig M \& Leng G 2006 Dendritic peptide release and peptide-dependent behaviours. Nature Reviews. Neuroscience 7 126-136. (doi:10.1038/ nrn1845)

Ludwig M, Sabatier N, Bull PM, Landgraf R, Dayanithi G \& Leng G 2002 Intracellular calcium stores regulate activity-dependent neuropeptide release from dendrites. Nature 418 85-89. (doi:10.1038/ nature00822)

McNeilly AS \& Ducker HA 1972 Blood levels of oxytocin in the female goat during coitus and in response to stimuli associated with mating. Journal of Endocrinology 54 399-406. (doi:10.1677/joe.0.0540399)

Melander SE 1961 Oxytocinase activity of plasma of pregnant women. Nature 191 176-177. (doi:10.1038/191176a0)

Moody KM \& Adler NT 1995 The role of the uterus and cervix in systemic oxytocin-PGE2 facilitated lordosis behavior. Hormones and Behavior 29 571-580. (doi:10.1006/hbeh.1995.1287)

Moos F, Poulain DA, Rodriguez F, Guerne Y, Vincent JD \& Richard P 1989 Release of oxytocin within the supraoptic nucleus during the milk ejection reflex in rats. Experimental Brain Research 76 593-602. (doi:10.1007/BF00248916)

Morris JF \& Pow DV 1991 Widespread release of peptides in the central nervous system: quantitation of tannic acid-captured exocytoses. Anatomical Record 231 437-445. (doi:10.1002/ar.1092310406)

Moss RL, Dyball RE \& Cross BA 1972 Excitation of antidromically identified neurosecretory cells of the paraventricular nucleus by oxytocin applied iontophoretically. Experimental Neurology 34 95-102. (doi:10.1016/ 0014-4886(72)90190-2)

Murphy MR, Seckl JR, Burton S, Checkley SA \& Lightman SL 1987 Changes in oxytocin and vasopressin secretion during sexual activity in men. Journal of Clinical Endocrinology and Metabolism 65 738-741. (doi:10.1210/jcem-65-4-738)

Neumann ID \& Landgraf R 2012 Balance of brain oxytocin and vasopressin implications for anxiety, depression, and social behaviors. Trends in Neurosciences 35 649-659. (doi:10.1016/j.tins.2012.08.004)

Nishimori K, Young LJ, Guo Q, Wang Z, Insel TR \& Matzuk MM 1996 Oxytocin is required for nursing but is not essential for parturition or reproductive behavior. PNAS 93 11699-11704. (doi:10.1073/pnas.93. 21.11699)

O’Byrne KT, Ring JP \& Summerlee AJ 1986 Plasma oxytocin and oxytocin neurone activity during delivery in rabbits. Journal of Physiology $\mathbf{3 7 0}$ 501-513. (doi:10.1113/jphysiol.1986.sp015947)

Onaka T, Yagi K \& Hamamura M 1988 Vasopressin secretion: suppression after light and tone stimuli previously paired with footshocks in rats. Experimental Brain Research 71 291-297. (doi:10.1007/BF00247489)

Onaka T, Serino R \& Ueta Y 2003 Intermittent footshock facilitates dendritic vasopressin release but suppresses vasopressin synthesis within the rat supraoptic nucleus. Journal of Neuroendocrinology $\mathbf{1 5}$ 629-632. (doi:10.1046/j.1365-2826.2003.01053.x)

Paisley AC \& Summerlee AJ 1984 Activity of putative oxytocin neurone during reflex milk ejection in conscious rabbits. Journal of Physiology 347 465-478. (doi:10.1113/jphysiol.1984.sp015076)

Pickles VR 1953 Blood-flow estimations as indices of mammary activity. Journal of Obstetrics and Gynaecology of the British Empire 60 301-311. (doi:10.1111/j.1471-0528.1953.tb14063.x)

Popper K 1959 The Logic of Scientific Discovery. London, UK: Hutchinson \& Co.

Qin J, Feng M, Wang C, Ye Y, Wang PS \& Liu C 2009 Oxytocin receptor expressed on the smooth muscle mediates the excitatory effect of oxytocin on gastric motility in rats. Neurogastroenterology and Motility 21 430-438. (doi:10.1111/j.1365-2982.2009.01282.x)

Raisman G 1997 An urge to explain the incomprehensible: Geoffrey Harris and the discovery of the neural control of the pituitary gland. Annual

Published by Bioscientifica Ltd 
Review of Neuroscience 20 533-566. (doi:10.1146/annurev.neuro.20. 1.533)

Richard P, Moos F \& Freund-Mercier MJ 1991 Central effects of oxytocin. Physiological Reviews 71 331-370.

Rossoni E, Feng J, Tirozzi B, Brown D, Leng G \& Moos F 2008 Emergent synchronous bursting of oxytocin neuronal network. PLoS Computational Biology 4 e1000123. (doi:10.1371/journal.pcbi. 1000123)

Russell JA, Leng G \& Douglas AJ 2003 The magnocellular oxytocin system, the fount of maternity: adaptations in pregnancy. Frontiers in Neuroendocrinology 24 27-61. (doi:10.1016/S0091-3022(02)00104-8)

Selye H 1934 On the nervous control of lactation. American Journal of Physiology 107 535-538.

Siegenthaler J, Walti C, Urwyler SA, Schuetz P \& Christ-Crain M 2014 Copeptin concentrations during psychological stress: the PsyCo study. European Journal of Endocrinology 171 737-742. (doi:10.1530/ EJE-14-0405)

Sudbury JR, Ciura S, Sharif-Naeini R \& Bourque CW 2010 Osmotic and thermal control of magnocellular neurosecretory neurons - role of an N-terminal variant of trpv1. European Journal of Neuroscience 32 2022-2030. (doi:10.1111/j.1460-9568.2010.07512.x)

Summerlee AJ 1981 Extracellular recordings from oxytocin neurones during the expulsive phase of birth in unanaesthetized rats. Journal of Physiology 321 1-9. (doi:10.1113/jphysiol.1981.sp013967)

Summerlee AJ \& Lincoln DW 1981 Electrophysiological recordings from oxytocinergic neurones during suckling in the unanaesthetized lactating rat. Journal of Endocrinology 90 255-265. (doi:10.1677/joe. $0.0900255)$

Summerlee AJ, Paisley AC, O’Byrne KT, Fairhall KM, Robinson IC \& Fletcher J 1986 Aspects of the neuronal and endocrine components of reflex milk ejection in conscious rabbits. Journal of Endocrinology $\mathbf{1 0 8}$ 143-149. (doi:10.1677/joe.0.1080143)

Sundsten JW, Novin D \& Cross BA 1970 Identification and distribution of paraventricular units excited by stimulation of the neural lobe of the hypophysis. Experimental Neurology 26 316-329. (doi:10.1016/ 0014-4886(70)90129-9)

Theodosis DT \& Poulain DA 1993 Activity-dependent neuronal-glial and synaptic plasticity in the adult mammalian hypothalamus. Neuroscience 57 501-535. (doi:10.1016/0306-4522(93)90002-W)
Tobin VA, Hurst G, Norrie L, Dal Rio FP, Bull PM \& Ludwig M 2004 Thapsigargin-induced mobilization of dendritic dense-cored vesicles in rat supraoptic neurons. European Journal of Neuroscience 19 2909-2912. (doi:10.1111/j.1460-9568.2004.03388.x)

Tobin VA, Hashimoto H, Wacker DW, Takayanagi Y, Langnaese K, Caquineau C, Noack J, Landgraf R, Onaka T, Leng G et al. 2010 An intrinsic vasopressin system in the olfactory bulb is involved in social recognition. Nature 464 413-417. (doi:10.1038/nature 08826)

Todd K \& Lightman SL 1986 Oxytocin release during coitus in male and female rabbits: effect of opiate receptor blockade with naloxone. Psychoneuroendocrinology 11 367-371. (doi:10.1016/03064530(86)90023-5)

Trudel E \& Bourque CW 2012 Circadian modulation of osmoregulated firing in rat supraoptic nucleus neurones. Journal of Neuroendocrinology 24 577-586. (doi:10.1111/j.1365-2826.2012.02298.x)

Urwyler SA, Schuetz P, Sailer C \& Christ-Crain M 2015 Copeptin as a stress marker prior and after a written examination - the CoEXAM study. Stress 18 134-137. (doi:10.3109/10253890.2014.993966)

Usta IM, Khalil A \& Nassar AH 2011 Oxytocin antagonists for the management of preterm birth: a review. American Journal of Perinatology 28 449-460. (doi:10.1055/s-0030-1270111)

Verney EB 1947 The antidiuretic hormone and the factors which determine its release. Proceedings of the Royal Society of London. Series B, Biological Sciences 135 25-106. (doi:10.1098/rspb.1947.0037)

de Vries GJ 2008 Sex differences in vasopressin and oxytocin innervation of the brain. Progress in Brain Research 170 17-27.

Wakerley JB \& Lincoln DW 1973 The milk-ejection reflex of the rat: a 20- to 40 -fold acceleration in the firing of paraventricular neurones during oxytocin release. Journal of Endocrinology 57 477-493. (doi:10.1677/joe. $0.0570477)$

Yagi K, Azuma T \& Matsuda K 1966 Neurosecretory cell: capable of conducting impulse in rats. Science 154 778-779. (doi:10.1126/science. 154.3750.778)

Young WS III, Shepard E, Amico J, Hennighausen L, Wagner KU, LaMarca ME, McKinney C \& Ginns EI 1996 Deficiency in mouse oxytocin prevents milk ejection, but not fertility or parturition. Journal of Neuroendocrinology 8 847-853. (doi:10.1046/j.1365-2826. 1996.05266.x)

Received in final form 7 April 2015

Accepted 15 April 2015

Accepted Preprint published online 21 April 2015 (c) 2015 Society for Endocrinology Printed in Great Britain
Published by Bioscientifica Ltd 